\title{
A Climatology of Snow-to-Liquid Ratio for the Contiguous United States
}

\author{
Martin A. Baxter, Charles E. Graves, and James T. Moore \\ Department of Earth and Atmospheric Sciences, Saint Louis University, St. Louis, Missouri
}

(Manuscript received 1 September 2004, in final form 6 December 2004)

\begin{abstract}
A 30-yr climatology of the snow-to-liquid-equivalent ratio (SLR) using the National Weather Service (NWS) Cooperative Summary of the Day (COOP) data is presented. Descriptive statistics are presented for 96 NWS county warning areas (CWAs), along with a discussion of selected histograms of interest. The results of the climatology indicate that a mean SLR value of 13 appears more appropriate for much of the country rather than the often-assumed value of 10 , although considerable spatial variation in the mean exists. The distribution for the entire dataset exhibits positive skewness. Histograms for individual CWAs are both positively and negatively skewed, depending upon the variability of the in-cloud, subcloud, and ground conditions.
\end{abstract}

\section{Introduction}

To forecast snowfall amounts for a winter extratropical cyclone (ETC), the forecaster employs a two-step process. First, current dynamic and thermodynamic fields must be analyzed in conjunction with numerical model forecasts to determine a quantitative precipitation forecast (QPF). This QPF represents the liquid equivalent expected to precipitate from the system. To convert this liquid equivalent to a snowfall amount, a snow-to-liquid-equivalent ratio (SLR) must be determined. An SLR value of 10 is often assumed as a mean value; however, this value may not be accurate for many locations and meteorological situations. Even if the forecaster has correctly forecasted the QPF, an error in the predicted SLR value may cause significant errors in forecasted snowfall amount-the forecast variable that is disseminated to the public. As an example, a QPF value of 0.25 in. may produce 2 in. of snowfall for an SLR value of 8, or 5.5 in. of snowfall for an SLR value of 22, a sizeable difference in terms of societal impacts.

As early as 1875, the U.S. Weather Bureau provided a typical SLR value of 10:1 to its observers, later instructing observers in 1894 that the 10:1 ratio was only

Corresponding author address: Martin A. Baxter, Dept. of Earth and Atmospheric Sciences, Saint Louis University, 329 Macelwane Hall, 3507 Laclede Ave., St. Louis, MO 63103.

E-mail: baxterma@eas.slu.edu a rough approximation (Henry 1917). In 1878 a 10:1 mean SLR value was determined for Toronto when an observer came to this conclusion after a long series of experiments (Potter 1965). A number of studies have shown that there is considerable variation from this estimate depending on location and various environmental parameters (e.g., Henry 1917; LaChapelle 1962; Grant and Rhea 1974; Doesken and Judson 1996; Super and Holroyd 1997; Judson and Doesken 2000; Roebber et al. 2003). Many National Weather Service (NWS) offices are aware of the variation in ratios and use either a climatological value or an empirical method based upon surface or in-cloud temperatures (Roebber et al. 2003). The NWS "New Snowfall to Estimated Meltwater Conversion Table" utilizes surface temperatures to estimate snowfall from its liquid equivalent (U.S. Department of Commerce 1996). It is only marginally effective, as it does not account for geographic location or in-cloud microphysical processes. Anecdotal evidence from NWS forecasters reveals that the table has been used operationally in at least some forecast offices, although it was not intended for operational use (Roebber et al. 2003).

\section{a. Factors affecting SLR}

Much of the research done on SLR is from the middle part of the twentieth century (e.g., Diamond and Lowry 1954; Bossolasco 1954; LaChapelle 1962), with the subject enjoying a recent revival (e.g., Judson and Doesken 2000; Roebber et al. 2003; Ware et al. 
2005, manuscript submitted to Wea. Forecasting). In contrast to previous studies that attempted to correlate SLR to various parameters, recent attempts focus on a more physically based method involving the analysis of microphysical processes that determine SLR.

The primary factor that determines SLR is the amount of air space trapped in the interstices between ice crystals within the newly fallen snow. Thus, to diagnose SLR the evolution of the ice crystals from their origin to the surface must be analyzed. As Roebber et al. (2003) discuss, not only must the in-cloud structure of the crystal be considered, but also subcloud processes and the degree of compaction at ground level. The initial ice crystal habit is dependent upon the temperature and degree of supersaturation with respect to ice and liquid water aloft (Magono and Lee 1966). Temperature will differentiate the basic habit of the crystal, with supersaturation delineating the specific crystal type (Pruppacher and Klett 1997). It is likely due to this fact that Roebber et al. (2003) found the impacts of moisture on SLR to be of secondary importance compared to the effects of temperature.

After the crystal forms, the surrounding environment will determine the type of growth. The process of crystal growth is very complex; as the crystal falls through the atmosphere it may encounter many different temperatures and degrees of saturation. This causes snowfall to consist not of one uniform habit, but of many different individual habits and superimposed habits known as polycrystals (Pruppacher and Klett 1997). As the crystal falls, the extent to which it undergoes either depositional growth (vapor to solid phase change) or growth by riming (liquid to solid phase change) will impact the amount of air space trapped within each crystal, and thus the subsequent SLR. Riming reduces interstice space and causes higher density (lower SLR) snow.

As Roebber et al. (2003) present, lower-level temperatures (and to a lesser extent, relative humidities) play a strong role in determining SLR. After falling from the cloud, ice crystals and snowflakes are further modified through sublimation (solid to vapor phase change) and melting. Sublimation occurs when ice crystals or snowflakes fall through an environment subsaturated with respect to ice, and is a function of crystal density and surface area. Snowflake or ice crystal melting is a function of air temperature near the hydrometeor surface, relative humidity, the size of the crystal or snowflake, and the amount of liquid water present. Snow densification at the surface begins at the time of snowfall and considerable increases in snow density can take place within a 24-h period as metamorphosis and crystal structural changes (known as destructive meta- morphism) take place within a new snow layer. The weight of the snow itself does not appear to be a controlling factor (LaChapelle 1962; Meister 1986). Temperature and vapor variations that cause crystal structural changes as well as the presence of strong wind compaction exert a greater control on densification. Compaction due to wind does play a strong role (Roebber et al. 2003), but no correlations between wind speed and SLR were found by Meister (1986).

\section{b. The need for a climatology}

To date no comprehensive climatology of SLR for the contiguous United States has been established. Knowledge of the seasonal mean of SLR might assist forecasters in establishing an initial estimate of SLR. The spatial variability of mean SLR over a region and the frequency of a given SLR value can assist the forecaster in refining the initial estimate. It is important to note that the relevant factors affecting SLR must be given careful consideration along with the statistical characteristics of SLR. It is the aggregate of the microphysical effects previously discussed that act to create the climatological statistics presented. Yet as many studies have shown (most recently Roebber et al. 2003), forecaster analysis of microphysical processes is exceedingly difficult, predominantly due to the lack of a finescale observing system. This difficulty further increases the need for a statistical analysis of SLR.

Climatology of SLR may be used in conjunction with other methods for determining SLR. One method involves the use of a neural network to predict SLR. The neural network is "trained" with the conditions (temperature, humidity, etc.) associated with SLR values for many cases. The neural network is then able to predict SLR for new cases based upon the nonlinear relationships derived from the training data. A neural network for use with SLR is established in Roebber et al. (2003). Use of this neural network may help to refine the initial estimate derived from climatology, as described in the discussion section.

The goals of this paper are to present the climatological values of SLR for the contiguous United States and examine the typical variability using histograms of SLR for various NWS county warning areas (CWAs). Section 2 describes the datasets and methodology used to perform this research. Section 3 presents the 30-yr climatology of SLR for the contiguous United States. Section 4 details the frequency of observed SLR values through the use of histograms for selected NWS CWAs. Section 5 includes a brief discussion on how the climatology of SLR may be used operationally. Finally, sec- 


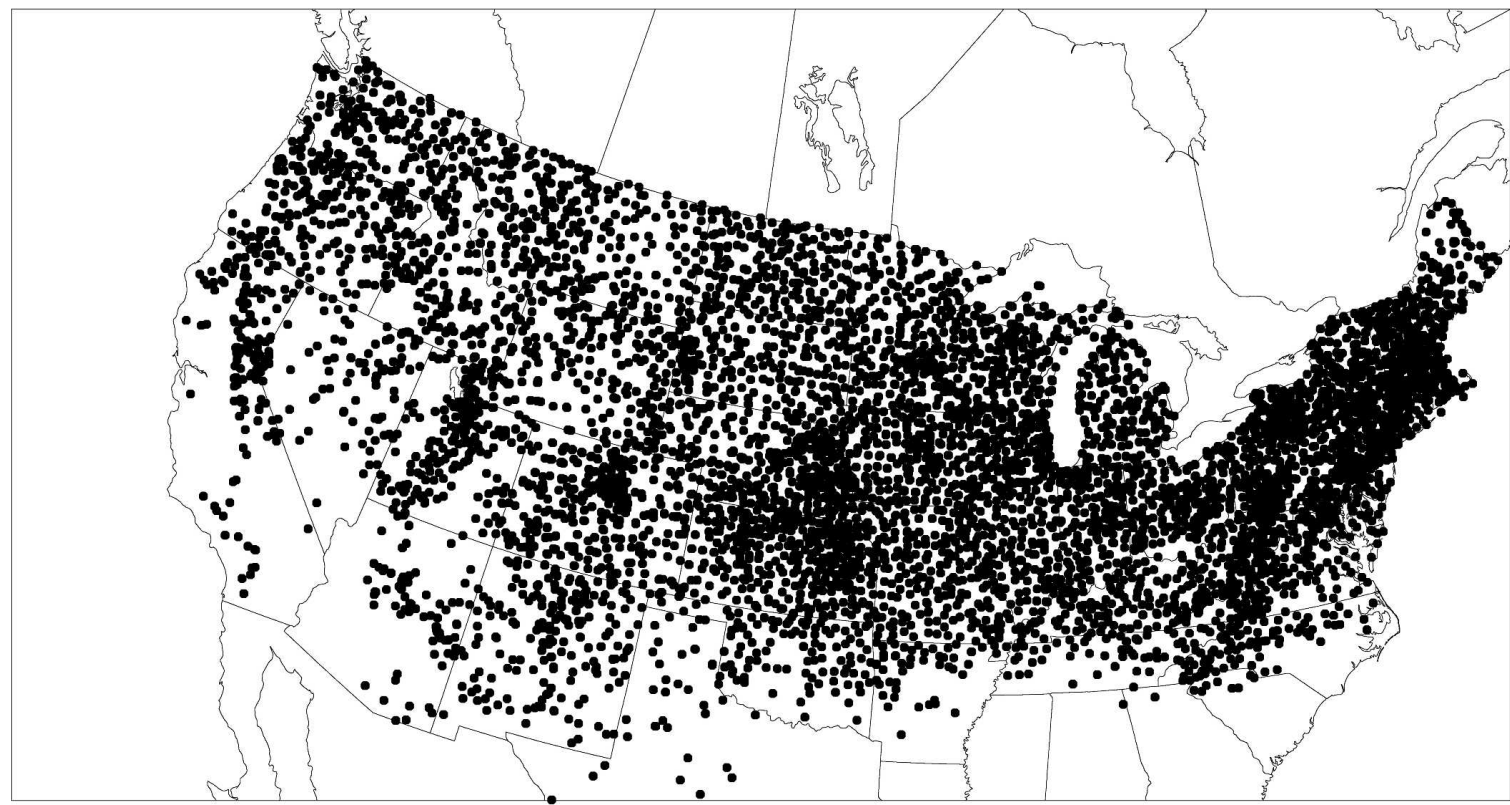

FIG. 1. Locations of COOP stations included in the climatology.

tion 6 summarizes the results and presents suggestions for future research.

\section{Dataset and methodology}

Surface data were obtained from the National Climatic Data Center (NCDC) Cooperative Summary of the Day (COOP) collection. These data represent daily observations taken by trained weather observers. Values for both liquid precipitation and snowfall were used in this study. SLR is simply the value for snow divided by the value for precipitation. Only snowfalls greater than $50.8 \mathrm{~mm}$ ( 2 in.) and liquid equivalents greater than $2.8 \mathrm{~mm}$ (0.11 in.) were included, following the standard set by Roebber et al. (2003). Reports that were estimated by the NCDC were not included. Only stations that had a minimum of 15 observations over the $30-\mathrm{yr}$ period were included.

A 30-yr (1971-2000) climatology was created from 7760 stations across the contiguous United States (Fig. 1). The climate statistics derived at each station were objectively analyzed using a Barnes (1973) objective analysis. Parameters $\kappa$ and $\gamma$ used in the objective analysis were $8000 \mathrm{~km}^{2}$ and 0.20 , respectively, resulting in a $50 \%$ resolution of the amplitude of $300-\mathrm{km}$ wavelength features (Koch et al. 1983). During the Barnes analysis, grid points were not only weighted according to distance, but also according to the number of observations for a given station. A nine-point smoother was applied to the field for additional smoothing. Grid points with no data values were given missing values, so that areas of no contours represent regions where no (or very little) snow fell.

\section{Climatology}

\section{a. Determination of bias in the climatology}

To determine the quality of the dataset, it is first necessary to evaluate the most recent COOP snow measurement guidelines. New snow is measured either once every $24 \mathrm{~h}$, or from the sum of four 6-hourly observations. The goal is to capture the maximum accumulation over the 24-h period. Observations are taken using either a ruler or snowboard, and observers are instructed to minimize wind impacts by obtaining a mean snow depth. The liquid equivalent is measured by melting the contents of a standard gauge. If the observer notices a discrepancy between the snow in the gauge and the snow on the ground, they are instructed to take a core sample from the snowboard (Doesken and Judson 1996).

There are four primary concerns with regard to snow measurement for COOP observers. Two are related to the effects of wind: the "undercatch" of precipitation in the gauge due to high wind speeds, and the settling of the snow due to wind and destructive metamorphism. High winds can cause precipitation to be underestimated in the gauge, resulting in an overassessment of SLR. Settling of the snow would lead to an underestimation of the amount of snow that fell, and thus an 


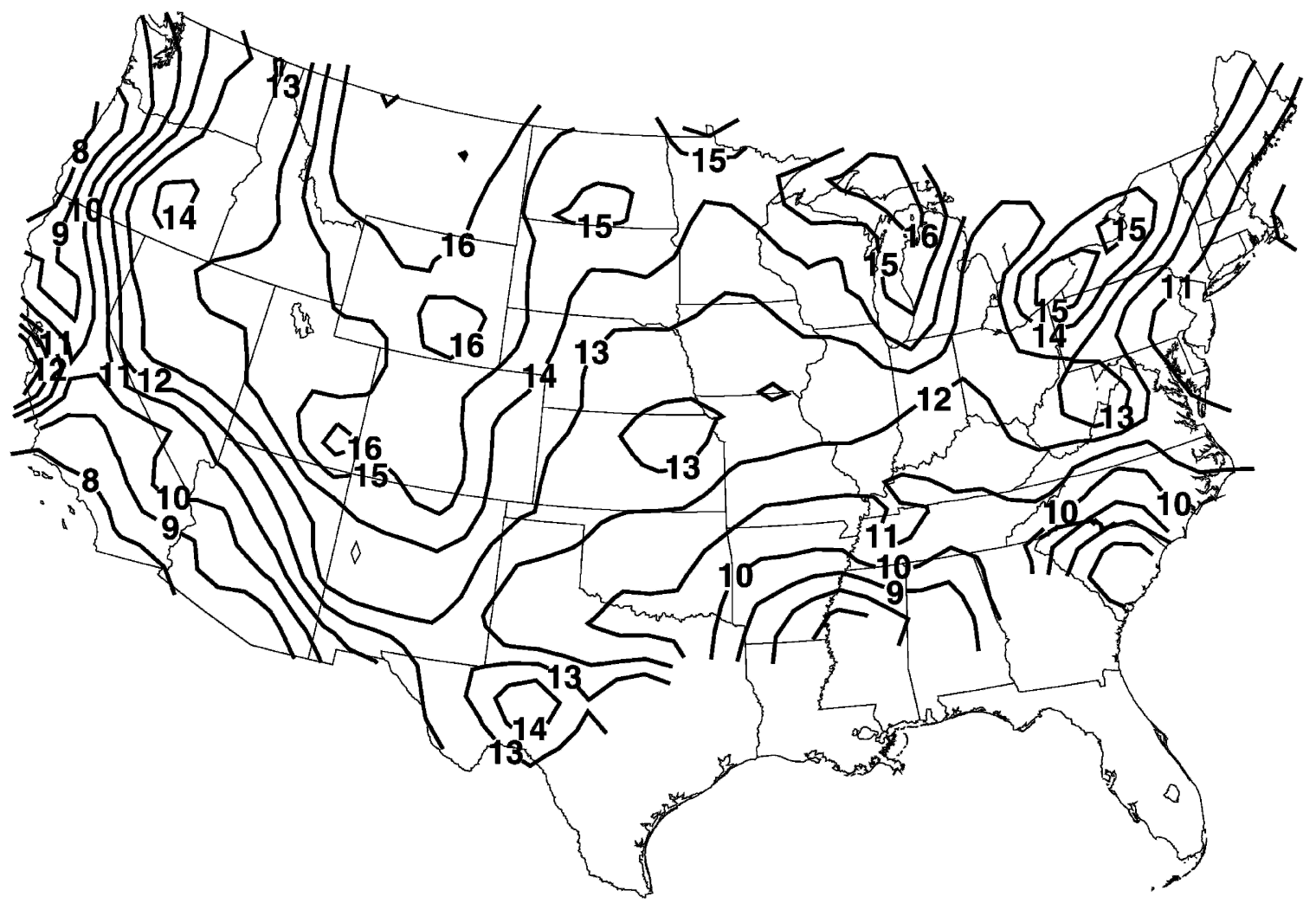

FIG. 2. Mean SLR values during 1971-2000.

underassessment of SLR. So the effects of wind are twofold and in opposite directions with respect to SLR. Third is the possibility of mixed precipitation or rain being included in the liquid-equivalent measurements. If mixed precipitation or rain occurs in the same day as the snow, the amount of precipitation in the gauge is increased, thus inappropriately reducing SLR values. The final concern is the possible tendency for observers to erroneously record SLR values of 10.0.

In examining the climatology of the mean SLR values, it is shown that mean values are consistently higher than 10 across most of the country, suggesting a more appropriate mean SLR for the United States in the range of 12-14 (although considerable spatial variation in the mean exists). If these results were erroneously skewed upward (in comparison to 10), this would imply that the predominant source of error is the undercatch due to high wind speeds. Unshielded gauges were shown to undercatch precipitation by $70 \%$ or more ( $40 \%$ for shielded gauges) during snowfall events with winds of $9 \mathrm{~m} \mathrm{~s}^{-1}$ or higher (Peck 1972; Larson and Peck 1974). Estimating a mean wind speed for a given storm for each gauge site is difficult due to gustiness. In addition, the gauge exposure varies at each site, causing varying wind impacts (Lott 1993). Meister (1986) found that the highest potential for measurement error must be assumed for small snow depths and high SLR values, thus, the standard for snowfalls to be included in this study was $50.8 \mathrm{~mm}$ ( $2 \mathrm{in}$.).

The other two sources of error are equally difficult to quantify. Changes in crystal structure result in decreasing snow depth as the amount of pore space decreases, causing the SLR to decrease (LaChapelle 1973). The warmer the temperature, the greater the decrease in SLR. The physics of the process of snow metamorphism dictate rapid settlement initially, followed by smaller decreases in SLR as time progresses (Judson and Doesken 2000). This suggests that conducting more frequent observations may not provide additional accuracy with respect to this problem. In the case of settling due to high winds, the effects will be highly nonuniform over a given area as a result of gustiness. Winds greater than $9 \mathrm{~m} \mathrm{~s}^{-1}$ can fracture and move crystals at the surface, causing surficial compaction and decreasing SLR (Kind 1981). If the prevalent wind speed is high, it is expected that for a given area new snowfall will settle more rapidly. In a sense, the "new" snow becomes "old" snow so quickly that, from an operational standpoint, it is difficult to define this effect as error.

With regard to the mixing of nonsnow precipitation 


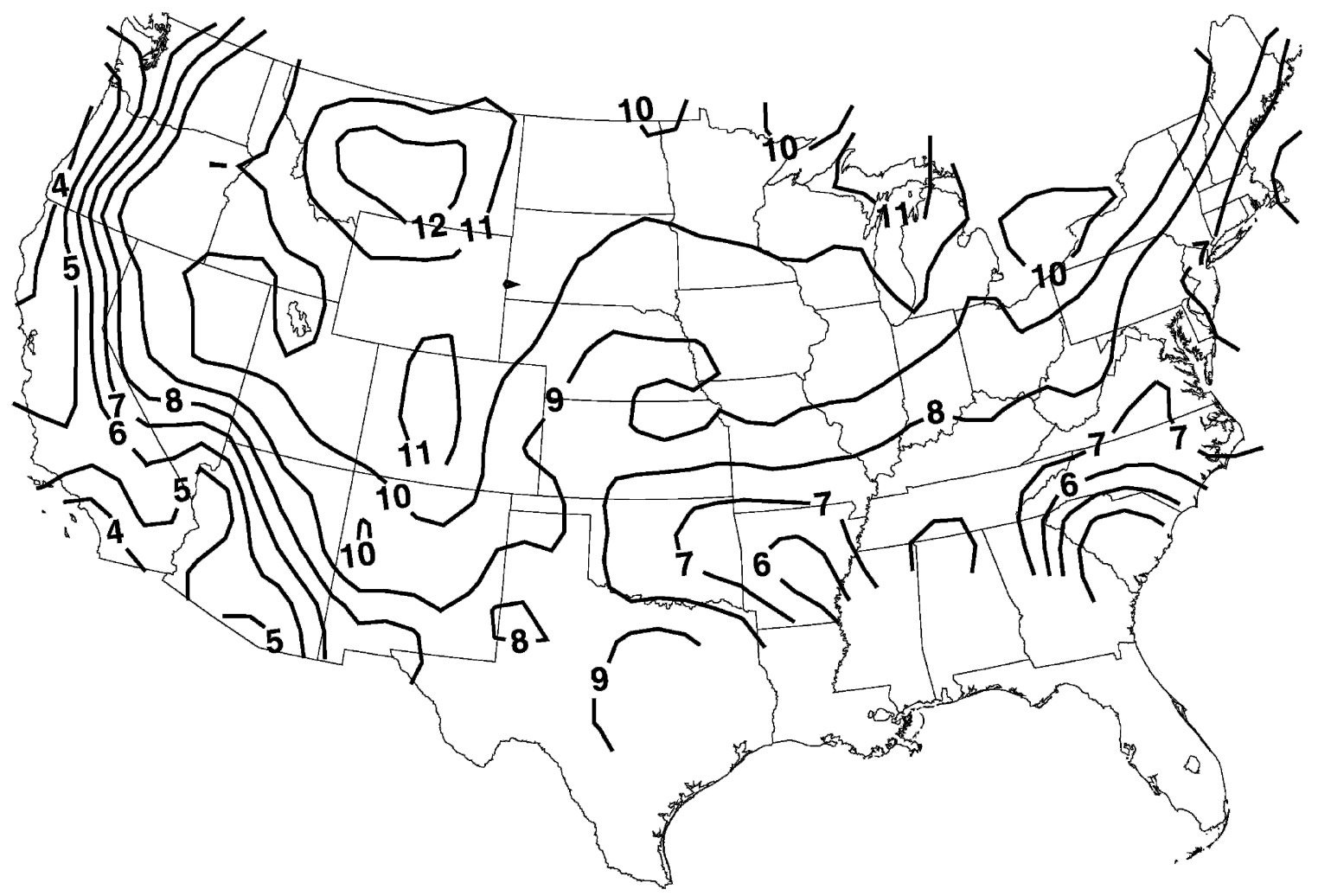

FIG. 3. The 25th percentile SLR values during 1971-2000.

into the dataset, throughout the period of record observers are not given separate categories other than PRCP (for liquid precipitation) and SNOW to record the amount of nonsnow precipitation. If snow occurs at any time during the day, the COOP observer may record a value for the snow amount, when rain or freezing rain may have also fallen during the time period. From 1980 forward, COOP observations indicated days with freezing rain or sleet. As the period prior to this accounts for approximately one-third of the dataset, days with nonsnow precipitation were not removed from the dataset. If days with nonsnow precipitation were excluded, the dataset would be inconsistent, as it is impossible to know which days prior to 1980 had nonsnow precipitation. This will act to decrease the values of SLR, as the PRCP amounts would be exaggerated due to the presence of both snow and freezing precipitation. It is expected that the early and late winter datasets may be more susceptible to this kind of error, as nonsnow precipitation is more likely when mean temperatures are warmer. In addition to a seasonal dependence, a latitudinal dependence is also concomitant.

Finally, it is not possible to determine if observers have a tendency to erroneously record an SLR value of 10 , as no method can be employed to determine how many of the SLR values of 10 are correctly measured values and how many are incorrect. The likely reason for any incorrect values is that the observer measured the snowfall and then assumed an SLR value of 10 to compute a liquid equivalent in lieu of an actual measurement. It is possible that this type of error occurs for other SLR values, but is likely most predominate for an SLR value of 10 due to the often used incorrect assumption of a mean SLR value of 10 . This type of error will be further discussed in the subsection of section 4.

In comparing the results of the mean SLR climatology with previous results for locations across the United States, considerable agreement is exhibited. In many of these studies considerable efforts were undertaken to minimize error (particularly Super and Holroyd 1997). The fact that the results of this study agree with these measurements implies some degree of offsetting between sources of error that act to inflate or reduce SLR (winds) and those that act to reduce it (inclusion of nonsnow precipitation and snowpack metamorphism). In using the climatology, it is best to consider the relative prevalence of each error source for a given region in order to best determine a mean SLR value. 


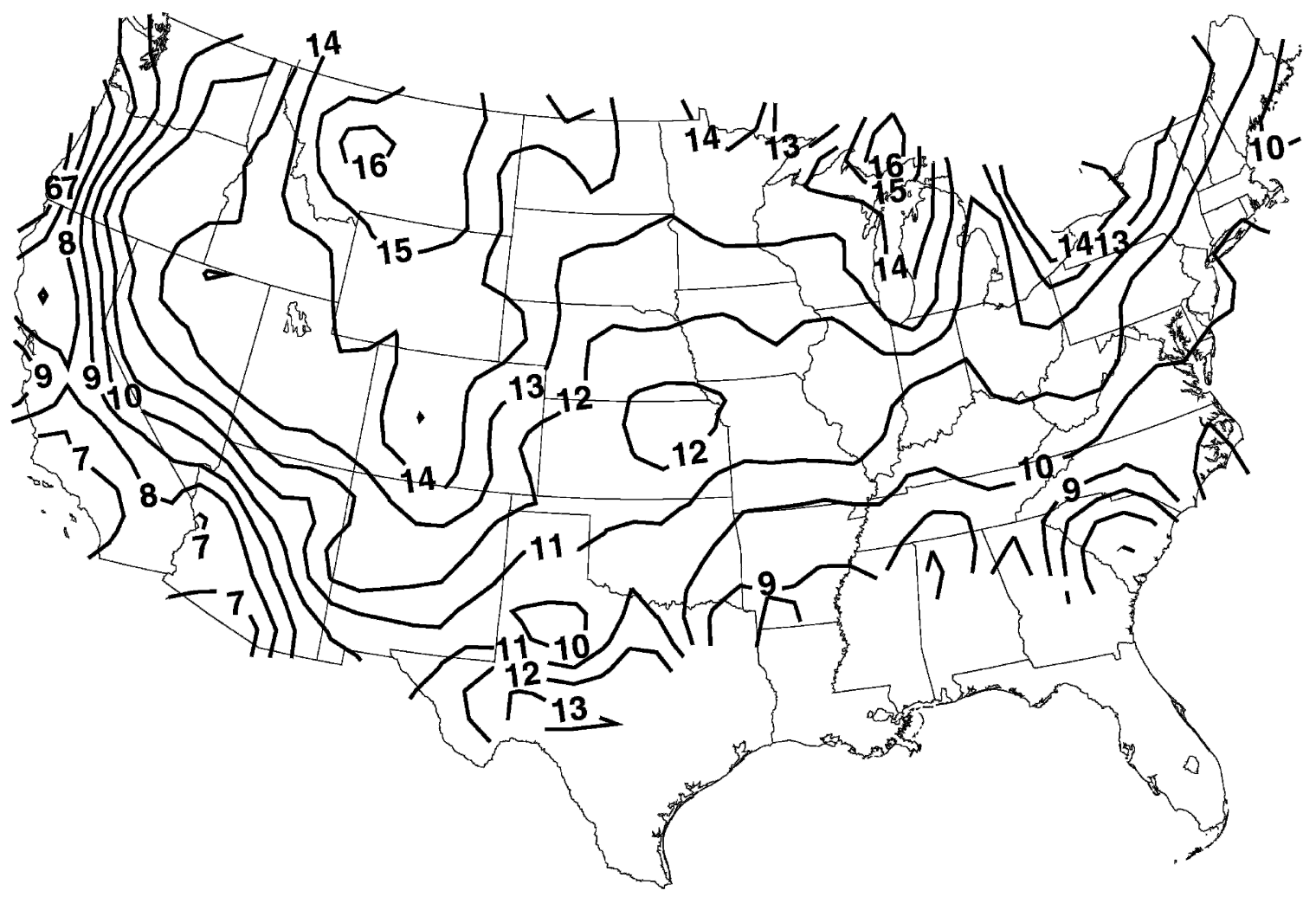

FIG. 4. The 50th percentile SLR values during 1971-2000.

\section{b. Mean $S L R$ values}

Qualitatively examining the objectively analyzed mean SLR (Fig. 2), the mountainous regions of the western United States and the northern Plains have higher mean SLR values in comparison to the rest of the country. (Color figures and an interactive view of the climatology using NWS CWAs are available online at http://www.eas.slu.edu/CIPS/Research/snowliquidrat. html.) Through Colorado, Wyoming, and Montana, mean SLR values are from 15 to 18 . Along the West Coast, mean SLR values abruptly decrease to between 9 and 11. The 13-15 values in western Texas are near the Edwards Plateau, so the higher mean SLR values are likely terrain induced. The Midwest mean SLR values gradually decrease from 15 in North Dakota to 11 in southern Missouri. Snows on the lee of the Great Lakes feature higher mean SLRs of 14-16. A small maximum of 13-14 appears on the West Virginia/ Virginia border; this feature is likely orographically related. Along the East Coast, mean SLR values decrease from 15 in eastern New York to 11 along the coast. As one would expect, lower SLRs occur in parts of the country that feature warmer, more moist air during the winter, and higher SLRs occur in parts of the country that feature colder, drier air during the winter.

\section{c. SLR stratified by percentile}

The entire collection of SLR values has been stratified according to percentile. The $x$ percentile plot depicts SLR values that $x$ percent of all SLR values fall below. The same relative patterns displayed in the plot for mean SLR are reflected in the percentile plots. The 25th percentile plot (Fig. 3) contains the smoothest signal of the three. The gradient is weaker in the East than it is in the West. This is likely due to the fact that high SLR values are dominant in the lee of the lakes, and their impacts do not show up in the lower end of the spectrum. Otherwise, the plot indicates that fairly low SLR values $(<10)$ are possible throughout the United States. The 50th percentile plot (Fig. 4) is comparable to the mean. This would indicate that the data exhibits little skewness, and that the distribution is symmetric about the mean. Yet this interpretation may be misleading, as histograms over NWS CWAs exhibit slightly positively skewed distributions in many locations (see the subsection of section 4). In the 75th percentile plot (Fig. 5), considerable variation is seen, with values ranging from 9 to 20 . To the lee of the Great Lakes, SLR values greater than 20 are common. SLR values on this order are also seen in the mountainous West.

Describing the range of SLR values for the 25th-75th 


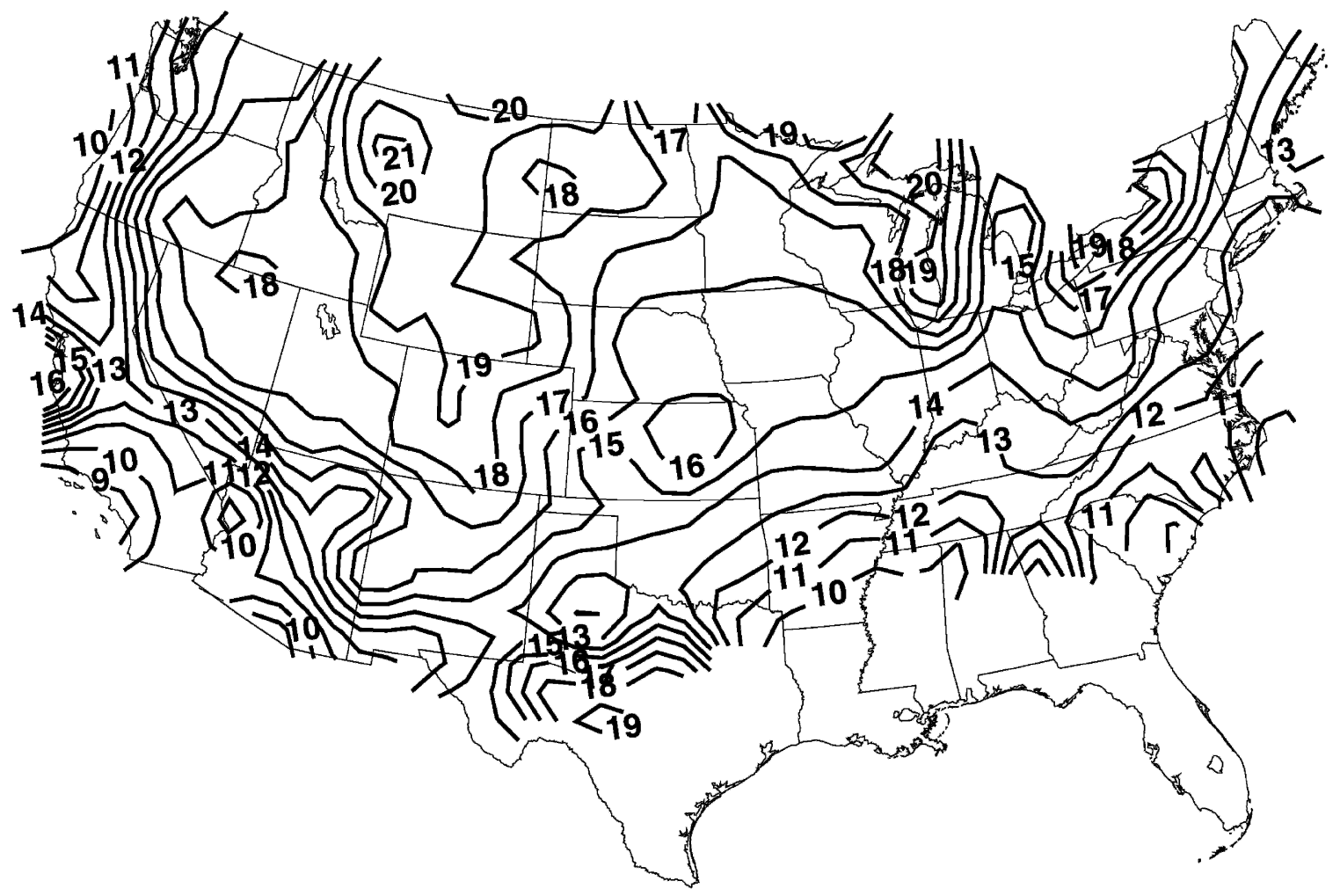

FIG. 5. The 75th percentile SLR values during 1971-2000.

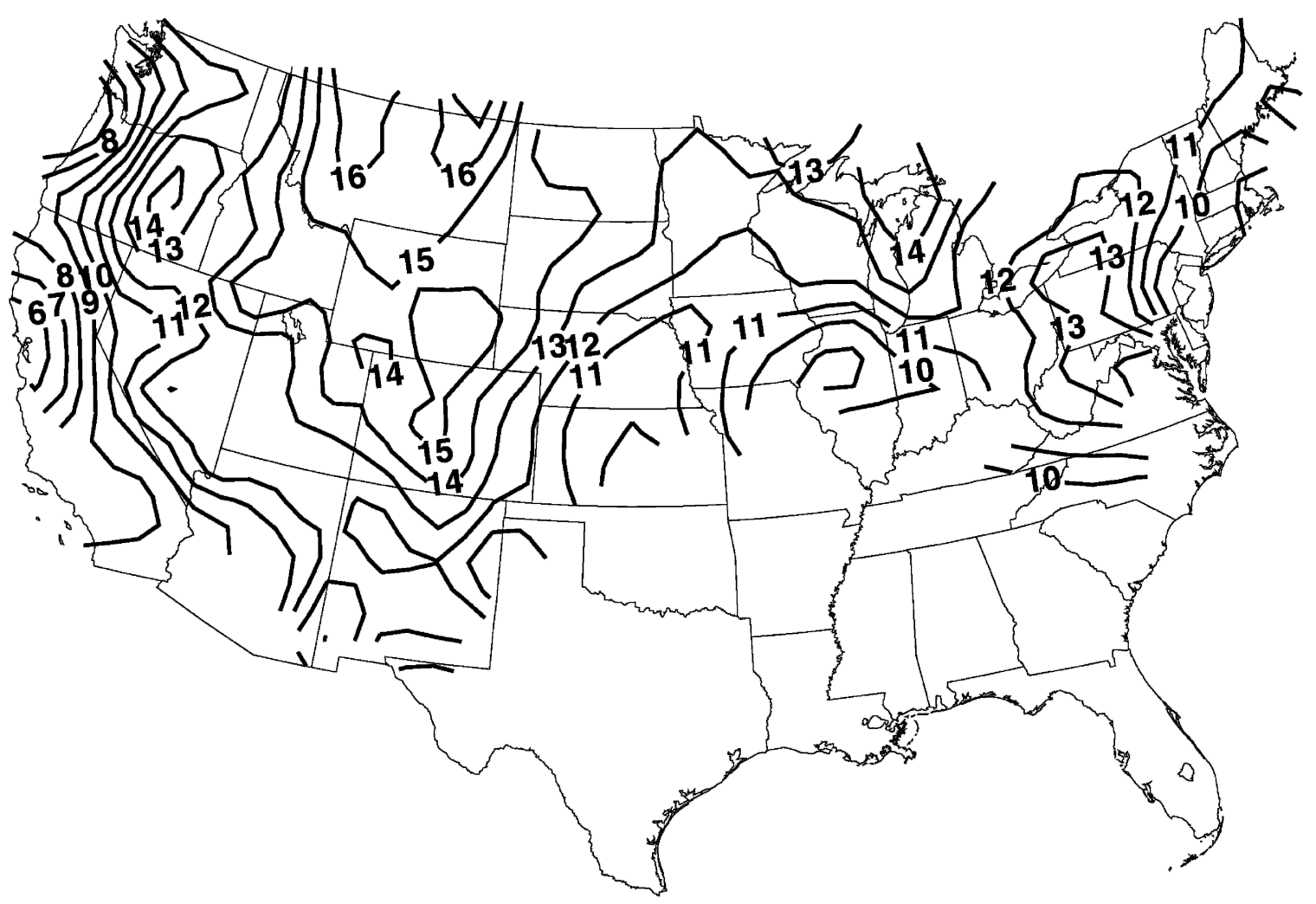

FIG. 6. Mean SLR (1971-2000) values for Oct and Nov. 


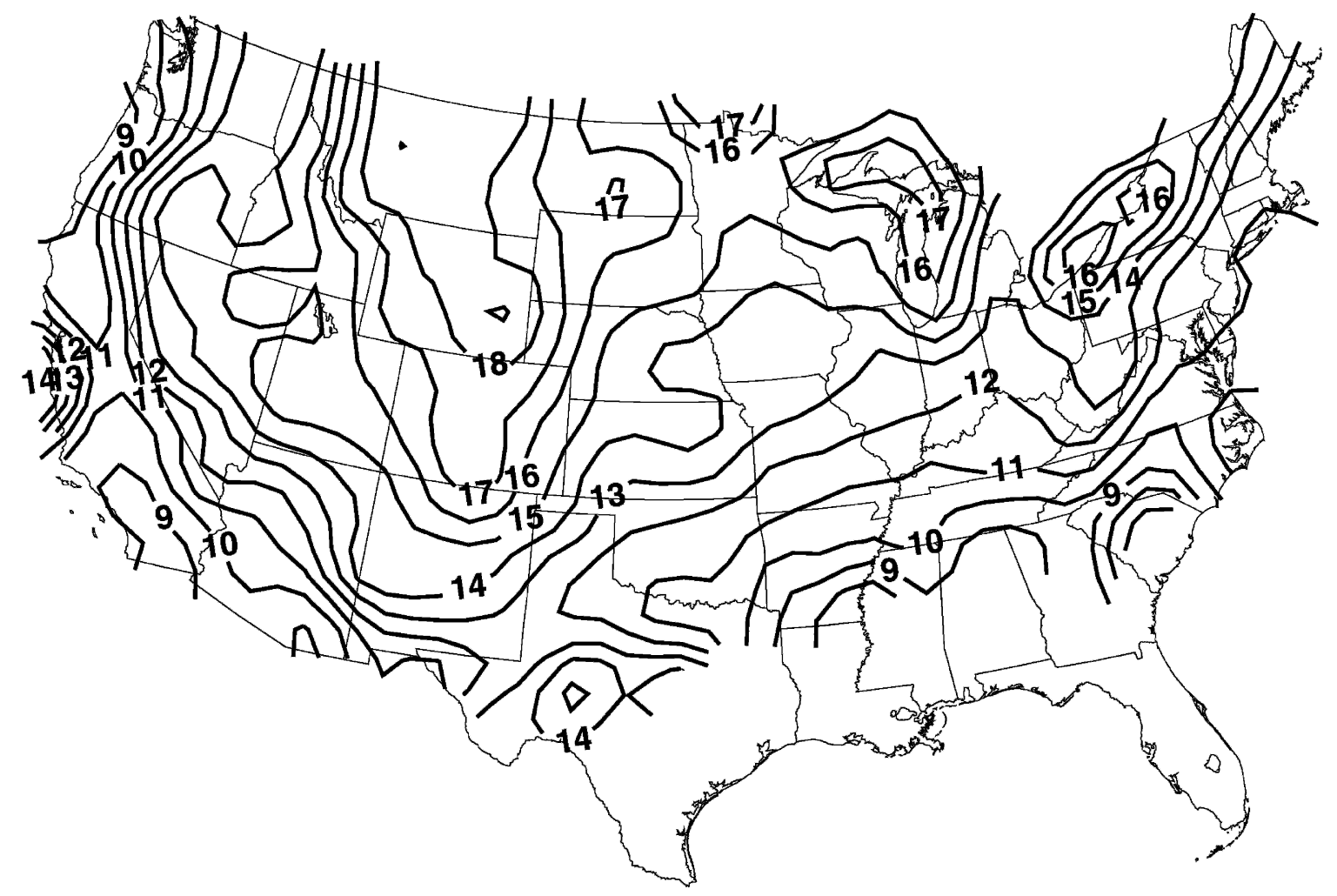

FIG. 7. Mean SLR (1971-2000) values for Dec, Jan, and Feb.

percentiles will present a typical range of values for a given location. Values for the mountainous regions of the west range from 10 to 16 , values for the northern part of the Midwest feature a range from 10 to 16, and values for the East Coast range from 8 to 14 . The difference between the values for the 25th and 75th percentiles for these three locations is 6 . In the southern part of the Midwest, the range is 7-14, a difference of 7 . On the West Coast, the range is from 4 to 12 , a difference of 8 . The Great Lakes exhibit the largest spread of 10 , with values for the 25 th and 75 th percentiles ranging from 10 to 20 .

\section{d. Mean SLR stratified by season}

Seasonal plots were created in order to examine the seasonal changes in the spatial distribution of SLR. The data sample was divided into early winter, containing October and November (Fig. 6); midwinter, containing December, January, and February (Fig. 7); and late winter, containing March and April (Fig. 8). Again, the same general patterns observed in the mean are reflected in the seasonal plots. Examining the southward extent of the contours, we see that snowfall is more prevalent farther south during the late winter months as opposed to the early winter months. This may be due to the fact that the antecedent ground temperatures from midwinter will allow snow accumulation more readily than the warmer ground temperatures in early winter. In comparison to the midwinter months, the SLR values are lower in almost all areas of the country in both the early and late winter cases.

The seasonal variability of SLR is of interest in the lee of the Great Lakes. The strong difference in temperature between the lakes and northwest flow aloft produces significant vertical motion, often in the form of convective updrafts. The lakes are a considerable source of moisture when unfrozen, allowing substantial riming to occur. Crystals near shore exhibit significant riming, while farther inland crystals are less rimed as the updraft weakens and moisture is depleted (Jiusto and Weickmann 1973). This would imply lower SLR values near shore compared to farther inland. During the early winter period (Fig. 6) along the lee of lakes Erie and Ontario an SLR value of 12 is seen near the lakes, increasing to 13 farther inland. During the midwinter months (Fig. 7), as the lakes begin to freeze, a maximum SLR value of 16 is seen in the lee of the lakes. The degree of riming is reduced when less moisture is available from the lakes (Jiusto and Weickmann 1973), yet some of the processes that produce lake- 


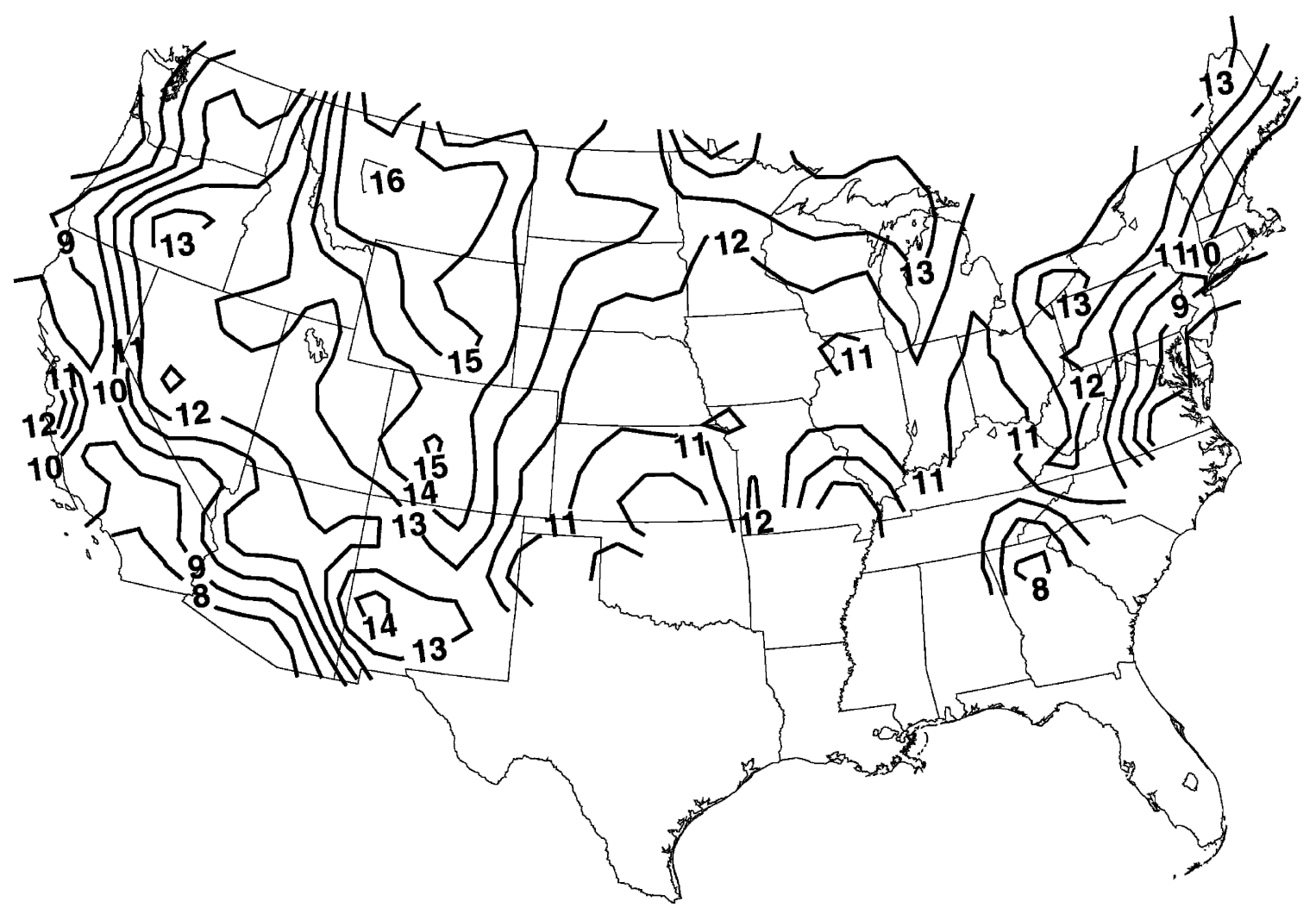

FIG. 8. Mean SLR (1971-2000) values for Mar and Apr.

effect snow are still present during these months to account for the local SLR maxima. In addition to the spatial variability of SLR due to season and proximity to the shore, regions in the lee of the Great Lakes also experience non-lake-effect snow. The frequency of lake-effect versus non-lake-effect snow was not examined in this study, thus the implications of these two "types" of events on the statistical properties of SLR are not discussed.

\section{Histograms of SLR}

Statistics for the histogram encompassing all SLR observations over the contiguous United States (Fig. 9) are shown in Table 1. Descriptive statistics for the contiguous United States were computed using either the entire dataset or the statistics (e.g., the means) from the 97 CWAs. Calculations were computed in the latter manner to effectively normalize the statistics as follows. In taking a mean of means, CWAs containing more snowfall observations were weighted the same as those containing less snowfall observations. This provides a more representative mean for the contiguous United States by accounting for bias in the dataset due to changes in the frequency of snowfall by location, but does not account for changes in the resolution of the observing sites.

The histogram for the entire dataset (Fig. 9) displays a mean of 13.53, a median of 12.14, and a mode of 10.0 . The same statistics for the CWA-derived dataset are lower, with a mean of 12.64 , and a median of 11.43. This is expected, as CWAs that receive less frequent snowfall typically feature lower SLR values. Lower values are also seen in the other descriptive statistics for the CWA-derived dataset. The entire dataset has higher values than the CWA-derived dataset for standard deviation $(7.05$ versus 6.67$)$, 25 th percentile $(9.26$ versus 8.48 ), and 75 th percentile (16.67 versus 15.37 ).

The skewness of the entire dataset is more positive than that of the dataset compiled using the statistics from the 97 CWAs, as evidenced by the Yule-Kendall index $(\mathrm{Y}-\mathrm{K})$. The $\mathrm{Y}-\mathrm{K}$ index is a more resistant and robust measure of skewness than the sample skewness coefficient, as it minimizes the impacts of outliers by measuring the skewness of the central $50 \%$ of the data (Wilks 1995). It is computed as

$$
\gamma_{\mathrm{YK}}=\frac{q_{0.25}-2 q_{0.5}+q_{0.75}}{q_{0.75}-q_{0.25}},
$$




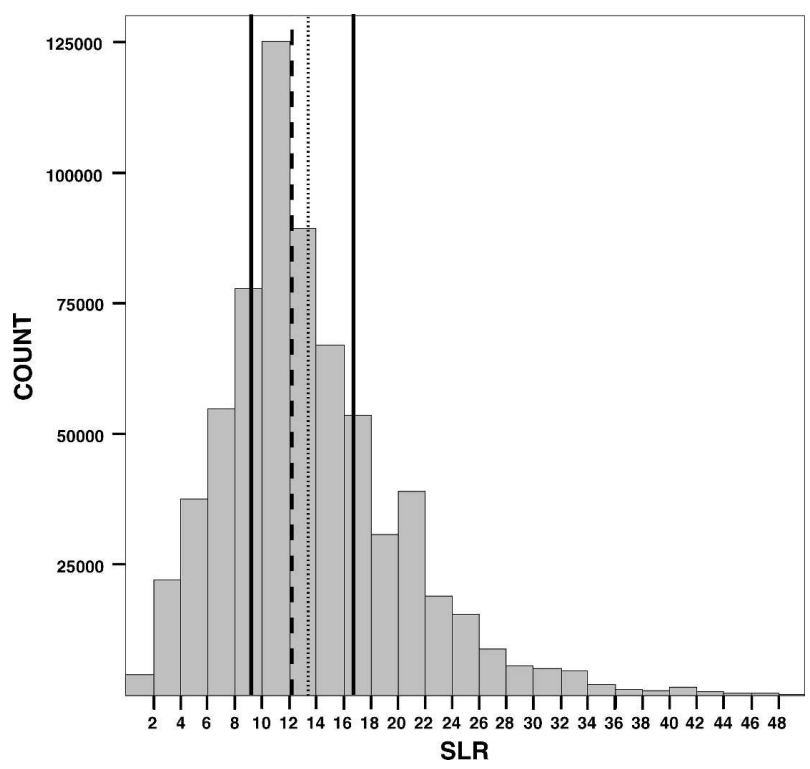

FIG. 9. Histogram for the entire dataset of SLR. Solid lines represent 25 th and 75 th percentiles, the long dashed line represents the median, and the short dashed line represents the mean.

where $q_{0.25}$ represents the 25 th percentile value, $q_{0.5}$ represents the 50th percentile value (median), and $q_{0.75}$ represents the 75 th percentile value. The $\mathrm{Y}-\mathrm{K}$ index varies from -1.0 to +1.0 . The positive skewness values of 0.221 for the entire dataset and 0.14 for the CWAderived set indicate that the range of values from the median (50th percentile) to the 75th percentile is greater than the range of values from the 25 th percentile to the median.

A previous climatology (1973-94) performed by Roebber et al. (2003) included 1650 events at 28 stations with a mean of 15.6 and a median of 14.1. The same stations were investigated using 24-h COOP data, producing 4257 snowfall observations during 1973-94. The mean and median using the COOP data were 13.5 and 12.3 , respectively. One possible reason for the discrepancy in the statistics between the two studies lies in the time scale of the measurements taken. Roebber et al. (2003) used 6-hourly snowfall observations from the U.S. Air Force surface climatic database (DATSAV2) and hourly precipitation data from the NCDC TD-3240 dataset. The time scale of the measurements affects the extent of settling of the snow; the longer snow is allowed to compact, the lower the SLR will be.

Table 2 presents descriptive statistics for the 97 CWAs that contained enough snowfall to meet the quality control requirements. The number of observations ranged from 15 for the Peachtree City, Georgia, CWA to 29311 for the Salt Lake City, Utah, CWA. Select histograms for CWAs with statistical characteristics of interest are presented. In the following discussion, CWA statistics are considered if there were at least 1000 observations.

The Glasgow, Montana, CWA (Fig. 10) had the highest mean SLR of 16.7, followed by the Marquette, Michigan, CWA and the Great Falls, Montana, CWA with 16.6. These locations likely feature high mean SLR values due to the preponderance of cold temperatures and/or lake-effect snow. In comparing the Glasgow histogram to the histogram for the entire dataset, the histogram is shifted toward higher SLR values and the peak is flatter, indicating that a range of values about the peak are equally as frequent. The central $50 \%$ of the data are symmetrical, with a Y-K value of 0.0. The Sacramento, California, CWA (Fig. 11) featured the lowest mean SLR value of 9.0. Snowfall in the Sacramento CWA likely features considerable riming as warm, moist, marine air is orographically lifted. In comparison to the histogram for the entire dataset, the histogram is shifted toward lower SLR values, and the frequency of observations below the mean are more comparable in magnitude to the frequency value at the peak of the curve. The central $50 \%$ of the curve is slightly negatively skewed (one of the few negatively skewed distributions), with a Y-K value of -0.03 .

The Buffalo, New York, CWA (Fig. 12) featured the highest standard deviation, with a value of 8.6. As discussed in section $3 \mathrm{~d}$, the spatial variability of SLR in

TABLE 1. Descriptive statistics for the entire dataset, the CWA-derived dataset, the study by Roebber et al. (2003), and a subset of the entire dataset containing the stations and time period used by Roebber et al. (2003).

\begin{tabular}{lcccr}
\hline \hline & Entire dataset & CWA-derived dataset & Roebber et al. (2003) & Current study subset \\
\hline Mean & 13.53 & 12.64 & 15.6 & 13.46 \\
Median & 12.14 & 11.43 & 14.1 & 12.3 \\
Mode & 10.0 & - & 10.0 & 10.0 \\
Std dev & 7.05 & 6.67 & - & - \\
25th percentile & 9.26 & 8.48 & - & - \\
75th percentile & 16.67 & 15.37 & - & - \\
Y-K & 0.221 & 0.14 & 1650 events & 4257 \\
Observations & 668832 & 668832 & 28 & 28 \\
Stations & 7760 & 76 CWAs & \\
\hline
\end{tabular}


TABLE 2. Descriptive statistics for 97 CWAs.

\begin{tabular}{|c|c|c|c|c|c|c|c|c|c|c|c|c|c|c|c|}
\hline CWA & Avg & 50 & $\begin{array}{l}\text { Std } \\
\text { dev }\end{array}$ & 75 & 25 & No. & $\mathrm{Y}-\mathrm{K}$ & CWA & Avg & 50 & $\begin{array}{l}\text { Std } \\
\text { dev }\end{array}$ & 75 & 25 & No. & $\mathrm{Y}-\mathrm{K}$ \\
\hline Glasgow, MT & 16.7 & 15.8 & 7.3 & 20 & 11.6 & 2397 & 0.00 & El Paso, TX & 12.5 & 11.1 & 6.6 & 15 & 8.6 & 888 & 0.22 \\
\hline Marquette, MI & 6.6 & 15 & 8.1 & 20 & 11.1 & 12039 & 0.12 & Reno, NV & 12.5 & 11.5 & 6.9 & 15.8 & 8.2 & 6831 & 0.13 \\
\hline Great Falls, MT & 6.6 & 15.4 & 7.8 & 20 & 11.3 & 15933 & 0.06 & Peachtree Cty, GA & 12.5 & 10.1 & 7.5 & 15.7 & 5.3 & 15 & 0.08 \\
\hline Gaylord, MI & 16.4 & 15 & 7.8 & 20 & 11 & 11879 & 0.11 & Pendleton, OR & 12.4 & 11 & 6.3 & 15 & 8.7 & 9048 & 0.27 \\
\hline Buffalo, NY & 16.3 & 15 & 8.6 & 20.6 & 10.3 & 16690 & 0.09 & Flagstaff, AZ & 12.4 & 10.9 & 6.9 & 15 & 8.3 & 6984 & 0.22 \\
\hline Billings, MT & 16 & 15 & 7.3 & 20 & 11 & 10663 & 0.11 & Dodge City, KS & 12.4 & 11.3 & 5.9 & 15 & 8.8 & 3125 & 0.19 \\
\hline Cheyenne, WY & 15.7 & 14.3 & 7.9 & 20 & 10 & 8281 & 0.14 & $\begin{array}{l}\text { Midland/Odessa, } \\
\text { TX }\end{array}$ & 12.4 & 11.1 & 6.7 & 15.2 & 8.3 & 304 & 0.19 \\
\hline Riverton, WY & 15.7 & 14.8 & 7.3 & 19.4 & 10.7 & 14133 & 0.06 & Central Illinois & 2.3 & 11.1 & 5.6 & 14.6 & 9.3 & 3584 & 0.32 \\
\hline Pueblo, CO & & 14.3 & 7.3 & 18.8 & 10.7 & 11252 & 0.11 & State College, PA & 2.3 & 10.9 & 6.6 & 15 & 8.3 & 11429 & 0.22 \\
\hline $\begin{array}{l}\text { Grand Junction, } \\
\text { CO }\end{array}$ & 15.2 & 14.2 & 6.8 & 18.7 & 10.7 & 21931 & 0.13 & Caribou, ME & 12.3 & 11.3 & 6 & 15 & 8.8 & 9502 & 0.19 \\
\hline Rapid City, SD & 5.1 & 13.6 & 7.5 & 18.8 & 10 & 12181 & 0.18 & San Angelo, TX & 12.3 & 10 & 9.3 & 15 & 6.2 & 78 & 0.14 \\
\hline Denver/Boulder, CO & 5.1 & 14 & 6.8 & 18.5 & 10.6 & 17997 & 0.14 & Albany, NY & 12.2 & 11 & 7 & 15 & 7.9 & 19187 & 0.13 \\
\hline Bismarck, ND & 4.9 & 13.5 & 7.1 & 18.2 & 10 & 12666 & 0.15 & Indianapolis, IN & 12.1 & 10.5 & 6 & 14.3 & 9.1 & 2544 & 0.46 \\
\hline $\begin{array}{l}\text { Grand Rapids, } \\
\text { MI }\end{array}$ & 14.8 & 13.2 & 7.6 & 18.5 & 10 & 7007 & 0.25 & Wilmington, $\mathrm{OH}$ & 12 & 10.4 & 6 & 14.3 & 8.7 & 3806 & 0.39 \\
\hline Duluth, MN & & 13.3 & 7.3 & 17.9 & 10 & 12493 & 0.16 & St & & 10.6 & 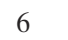 & 4.4 & 8.7 & 4566 & 33 \\
\hline Pocatello, ID & 14.8 & 13.5 & 7.5 & 17.9 & 10 & 5639 & 0.11 & $\begin{array}{l}\text { Detroit/Pontiac, } \\
\text { MI }\end{array}$ & 11.9 & 10.8 & 5.3 & 14.3 & 9 & 3481 & 0.32 \\
\hline Missoula, MT & 14.8 & 13.9 & 6.9 & 17.9 & 10.5 & 13371 & 0.08 & $\begin{array}{l}\text { Baltimore/ } \\
\text { Washington }\end{array}$ & 11.8 & 10.5 & 6.4 & 14.5 & 7.8 & 6216 & 0.19 \\
\hline Cleveland, $\mathrm{OH}$ & 14.5 & 12.8 & 7.5 & 18.5 & 10 & 7143 & 0.34 & Jackson, KY & 11.7 & 10.3 & 6.8 & 13.6 & 8.1 & 1326 & 0.20 \\
\hline $\begin{array}{l}\text { Albuquerque, } \\
\text { NM }\end{array}$ & 14.5 & 13.2 & 6.9 & 17.9 & 10 & 14116 & 0.19 & Medford, OR & 11.7 & 10.7 & 6.4 & 14.3 & 7.8 & 8779 & 0.11 \\
\hline Aberdeen, SD & 4.4 & 12.8 & 7.1 & 17.6 & 10 & 6266 & 0.26 & Norman, OK & 11.6 & 10.2 & 6.5 & 14.3 & 7.7 & 1848 & 0.24 \\
\hline Grand Forks, ND & 4.2 & 12.7 & 7 & 17.3 & 10 & 7873 & 0.26 & Mor & 1.6 & 10 & 8 & 13.9 & 7.5 & 10 & 0.22 \\
\hline $\begin{array}{l}\text { Salt Lake City, } \\
\text { UT }\end{array}$ & 14.2 & 13 & 7 & 17.5 & 9.8 & 29311 & 0.17 & Blacksburg, VA & 11.6 & 10.2 & 6.9 & 13.6 & 7.8 & 4808 & 0.17 \\
\hline Elko, NV & 14.1 & 12.8 & 6.7 & 17.3 & 10 & 5055 & 0.23 & $\begin{array}{l}\text { Gray/Portland, } \\
\text { ME }\end{array}$ & 11.6 & 10.6 & 5.9 & 14.3 & 7.8 & 21222 & 0.14 \\
\hline Monterey, CA & 14.1 & 10.3 & 11 & 18.7 & 4.8 & 46 & 0.21 & $\begin{array}{l}\text { Newport/Morehead, } \\
\text { NC }\end{array}$ & 11.6 & 10 & 7.4 & 10.4 & 8.9 & 31 & -0.47 \\
\hline North Indiana & & 12.1 & 7.4 & 17.2 & 10 & 5680 & 0.42 & Lubbock, TX & 11.4 & 10.7 & 5.2 & 13.1 & 8.3 & 344 & 0.00 \\
\hline Gree & & 12.5 & 6.5 & 16.7 & 10 & 11067 & 0.25 & & 11.3 & 10.4 & 5.6 & 13.8 & 7.6 & 2366 & 0.10 \\
\hline Fort Worth, TX & 3.8 & 12.2 & 7.2 & 17.6 & 9.7 & 21 & 0.37 & $\mathrm{KY}$ & 11.2 & 10 & 5.7 & 13.5 & 8.2 & 1937 & 0.32 \\
\hline Topeka, KS & 3.7 & 12.5 & 7 & 16.7 & 9.4 & 4567 & 0.15 & & 10.8 & 10 & 6.1 & 12.5 & 7.9 & 758 & 0.09 \\
\hline kee/Sullivan, WI & 3.6 & 12.1 & 6.8 & 16.7 & 9.6 & & 0.30 & & 10.8 & 10 & 5.8 & 12.6 & 7.6 & 2376 & 0.04 \\
\hline Pittsbu & 3.6 & 12 & 7.3 & & 9.3 & 103 & 0.27 & & 0.8 & 1 & 6.3 & 13 & .7 & 13 & 0.00 \\
\hline Cha & & 11.9 & & & 8 & & & & & & 6 & & 8 & & 02 \\
\hline Lacr & & 12. & 6.4 & 16 & 9.8 & & & & & 10 & 9 & 12.9 & 7.1 & & 0.00 \\
\hline es, MN & 3.5 & 12.5 & 6.3 & 16.7 & 9.7 & 13490 & 0.20 & Phila & 10.6 & 10 & 5.8 & 13 & 7 & 6205 & 0.00 \\
\hline Nortl & 3.4 & 12 & 6.8 & 16.7 & 9.2 & 7664 & 0.25 & Seat & 10.4 & 9.6 & 5.8 & 13 & 6.5 & 7865 & 0.05 \\
\hline Burlington, VT & 13.4 & 12.2 & 6.8 & 16.7 & 9.1 & 16607 & 0.18 & Wakefield, VA & 10.4 & 9.8 & 5.8 & 12.2 & 6.7 & 1286 & -0.13 \\
\hline Las Vegas, NV & 13.2 & 11.4 & 7.1 & 16.6 & 8.6 & 641 & 0.30 & Memphis, TN & 10.4 & 10 & 5.7 & 12.1 & 6.8 & 475 & -0.21 \\
\hline Goodland, KS & 13.2 & 11.9 & 6.7 & 16.6 & 8.9 & 4499 & 0.22 & $\begin{array}{l}\text { Greenville- } \\
\quad \text { Spartanburg, SC }\end{array}$ & 10.2 & 9.7 & 6.5 & 12.1 & 6.4 & 1986 & -0.16 \\
\hline Sioux & & & & & 9.2 & & & Little Rock, AR & & 9.8 & 5.9 & 11.7 & 6.4 & 740 & -0.28 \\
\hline Boi & & 12.2 & 6. & 1 & 9 & 938 & 0.13 & & 10 & 8.9 & 6.2 & 12.1 & 5.8 & 514 & 0.02 \\
\hline Chic & & 11. & & 15.9 & 9.6 & & 0.27 & & 9.6 & 9.5 & 4.8 & 11.1 & 6.5 & 524 & -0.30 \\
\hline Binghar & 13 & 11 & & 16 & 8 & & & & & 7.1 & 5 & 10.9 & 3.9 & & 0.09 \\
\hline Spokane, WA & & 12.2 & 5.9 & 15.8 & & 11734 & & & & 8.5 & 5.9 & 11.9 & 5.3 & 2336 & 0.03 \\
\hline Wichita, KS & 12.9 & 11.6 & 6.9 & 16.5 & 8.5 & 2942 & 0.23 & Shreveport, LA & 9.3 & 9.2 & 5 & 10 & 7.2 & 35 & -0.43 \\
\hline Kansas City, MO & 12.8 & 11.5 & 6.3 & 15.8 & 9.3 & 3674 & 0.32 & Portland, OR & 9.1 & 8.3 & 5.7 & 11.5 & 5.2 & 5528 & 0.02 \\
\hline Quad Cities, IA & 12.8 & 11.5 & 6 & 15.6 & 9.3 & 6029 & 0.30 & Sacramento, CA & 9 & 8.5 & 5.4 & 11.5 & 5.3 & 9916 & -0.03 \\
\hline Hastings, NE & 12.8 & 11.7 & 6.4 & 15.6 & 8.9 & 6895 & 0.16 & Huntsville, AL & 8.8 & 8.9 & 6 & 10.4 & 4 & 23 & -0.53 \\
\hline Amarillo, TX & 12.7 & 11.1 & 6.3 & 15 & 9.1 & 995 & 0.32 & San Diego, CA & 8.3 & 7.1 & 6.2 & 10 & 4.2 & 837 & 0.00 \\
\hline Omaha/Valley, NE & 12.7 & 11.7 & 6.2 & 15.8 & 8.9 & 9224 & 0.19 & Los Angles, CA & 7.7 & 7.5 & 5 & 10 & 4.4 & 74 & -0.11 \\
\hline Des Moines, IA & 12.6 & 11.4 & 6.2 & 15.2 & 9.1 & 8623 & 0.25 & & & & & & & & \\
\hline
\end{tabular}




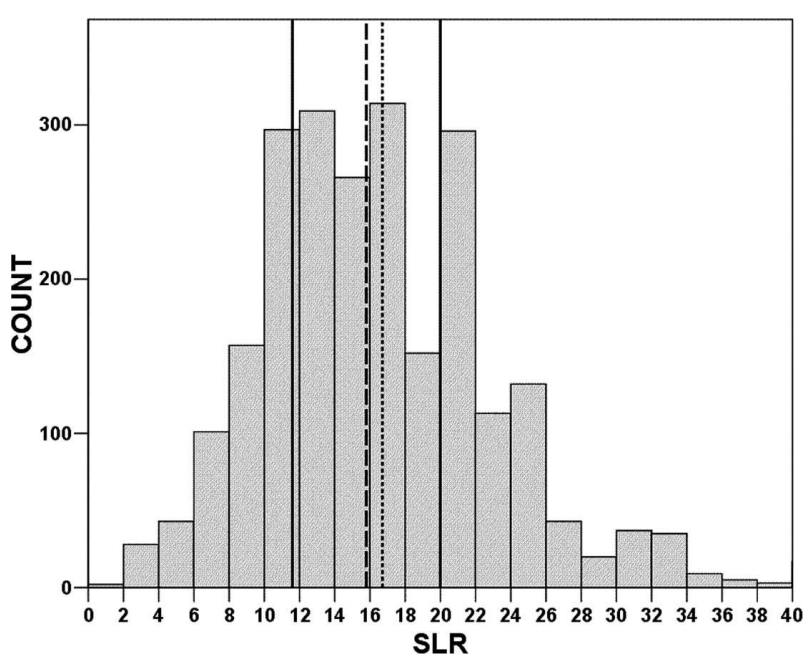

FIG. 10. Histogram of SLR for Glasgow, MT, CWA. Lines are the same as in Fig. 9.

regions in the lee of the Great Lakes depends upon both season and proximity to the shore. Compounding this complexity is the fact that the Buffalo CWA also receives non-lake-effect snowfall. Therefore, it is understandable that the Buffalo CWA histogram would feature a large standard deviation. In comparison to the histogram for the entire dataset, the histogram for the Buffalo CWA is shifted toward higher SLR values and features a much higher frequency of snowfall observations greater than the mean or median. The histogram has a bimodal appearance, with the primary peak located in the 10-12 bin and a secondary peak in the 20-22 bin. Due to the aforementioned spatial variability of SLR and presence of non-lake-effect and lakeeffect snow in this region, further research would be

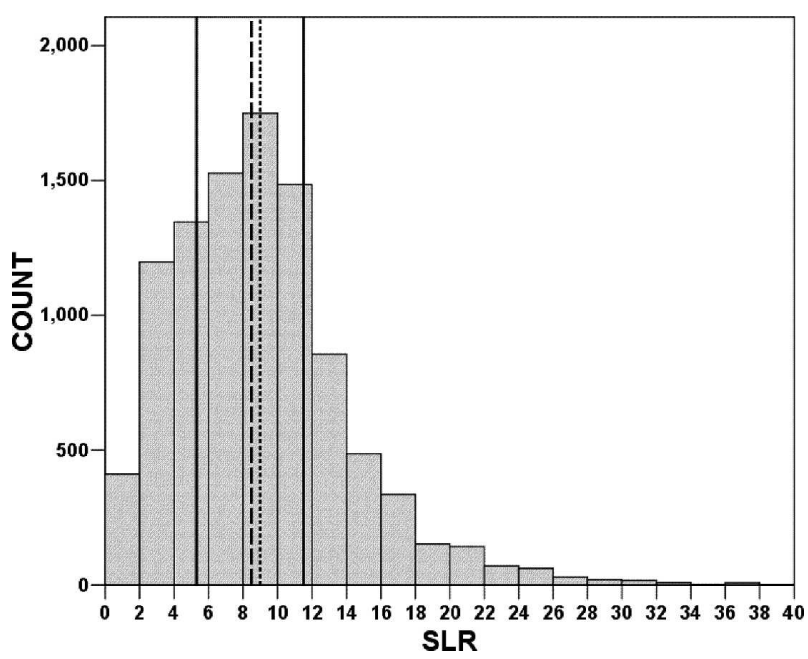

FIG. 11. Histogram of SLR for Sacramento, CA, CWA. Lines are the same as in Fig. 9.

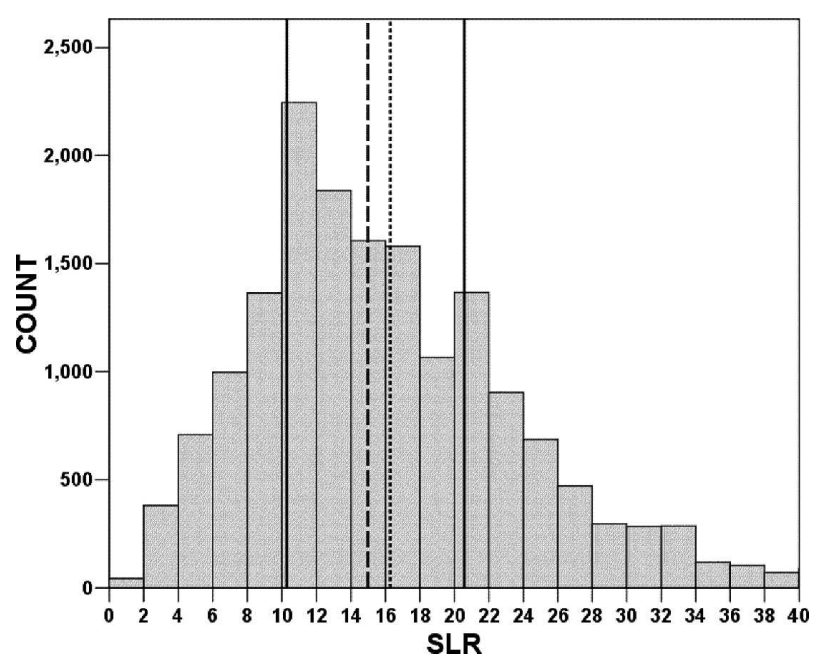

FIG. 12. Histogram of SLR for Buffalo, NY, CWA. Lines are the same as in Fig. 9.

necessary to determine the cause of this bimodal appearance. The Buffalo CWA histogram is slightly positively skewed, with a Y-K value of 0.09 . The Detroit, Michigan, CWA (Fig. 13) featured the lowest standard deviation, with a value of 5.3. The standard deviation is lower in the Detroit CWA histogram largely due to the preponderance of SLR values to fall into the 10-12 bin. The Detroit CWA histogram is strongly positively skewed, with a Y-K value of 0.32 .

\section{Histogram skewness}

The Indianapolis, Indiana, CWA histogram (Fig. 14) features the highest $\mathrm{Y}-\mathrm{K}$ value of 0.42 . Like the Detroit CWA histogram, it too contains a large majority of

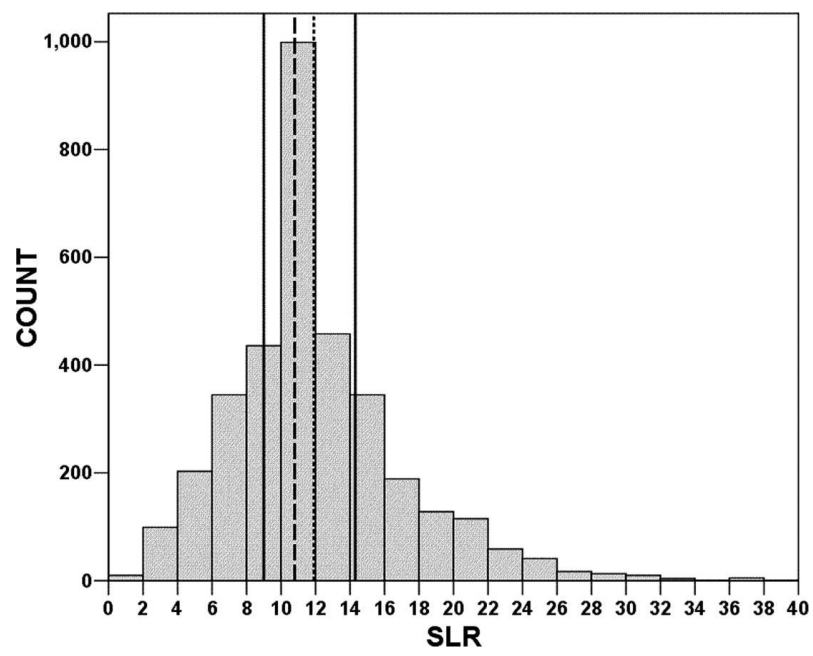

FIG. 13. Histogram of SLR for Detroit, MI, CWA. Lines are the same as in Fig. 9. 


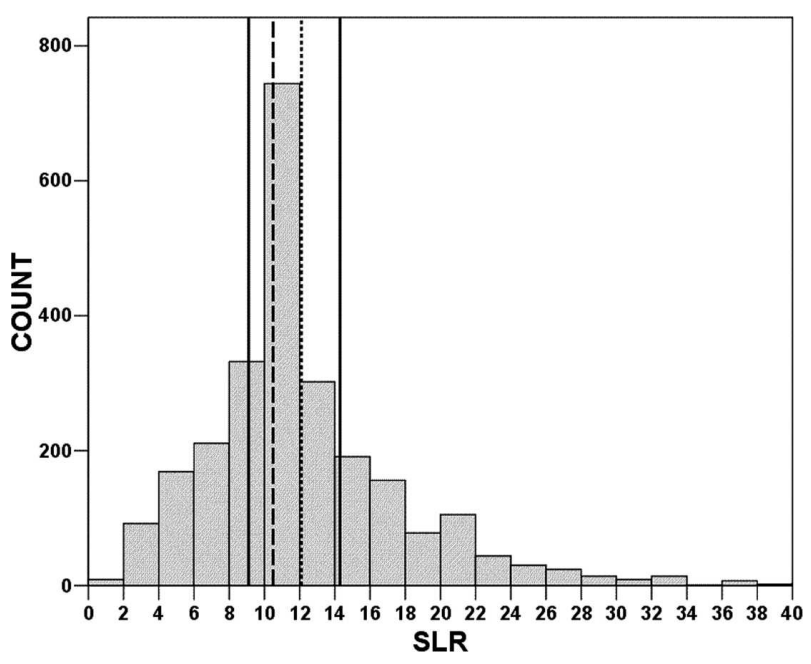

FIG. 14. Histogram of SLR for Indianapolis, IN, CWA. Lines are the same as in Fig. 9.

values within the 10-12 bin. The Philadelphia, Pennsylvania, CWA histogram (Fig. 15) features a $0.00 \mathrm{Y}-\mathrm{K}$ value, indicating no skewness in the central $50 \%$ of the data. The Greenville/Spartanburg, South Carolina, CWA histogram (Fig. 16) features the lowest Y-K value of -0.16 . The spatial variation of the $\mathrm{Y}-\mathrm{K}$ index displays some distinct patterns (Fig. 17). Negative values are clustered in the southeastern United States, where lower SLR values encompass a relatively high percentage of the dataset. This is likely due to an increased chance of snowfalls in relatively warm temperatures, or snow mixed with rain, sleet, or freezing rain. Values greater than 0.30 are clustered to the south of the Great Lakes, meaning that higher SLR values en-

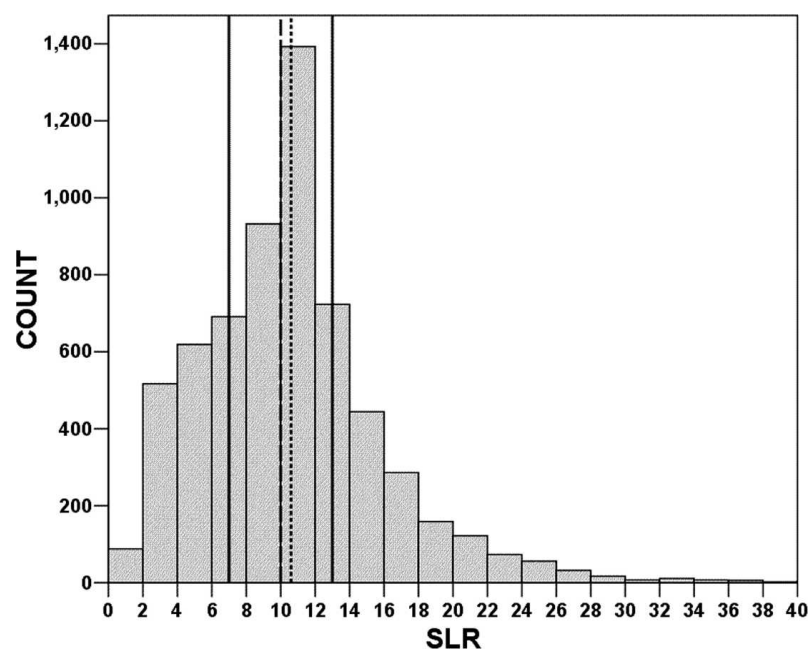

FIG. 15. Histogram of SLR for Phildelphia, PA, CWA. Lines are the same as in Fig. 9.

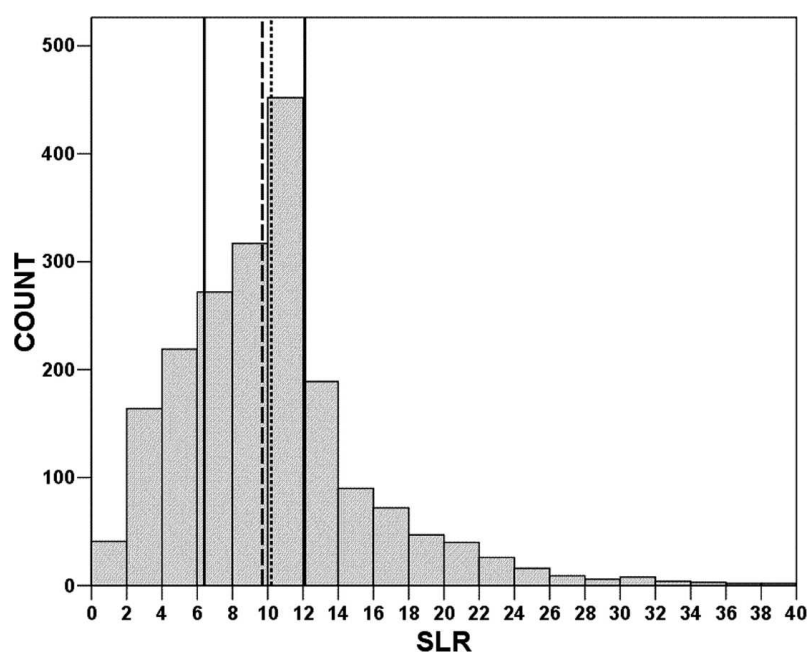

FIG. 16. Histogram of SLR for Greenville/Spartanburg, SC, CWA. Lines are the same as in Fig. 9.

compass a relatively high percentage of the dataset. Upon further examination of the histograms in this region, it becomes apparent that these unique $\mathrm{Y}-\mathrm{K}$ values may not be manifestations of a physical signal. The histograms for the Indianapolis CWA and the Detroit CWA contained a large spike in the 10-12 bin. For CWAs where an SLR value of 10.0 fell between the 50th and 75th percentiles, an increase in the Y-K index was concomitant with an increase in the percentage of values that were equal to 10.0 (Fig. 18). It is unknown whether this region actually does contain anomalously frequent 10.0 SLR values, or that the tendency of observers to erroneously record SLR values of 10.0 is higher in this region. It may be possible that the tendency of observers to erroneously record SLR values of 10.0 is the same everywhere, but the effect is magnified in this region due to a higher frequency of 10.0 SLR values actually occurring in comparison with other areas.

\section{Discussion}

As previously mentioned, the climatological statistics presented in this study represent a useful initial estimate for determining SLR, and this initial estimate should be modified according to the details of the meteorological situation. One way of revising this initial estimate is through comparing the climatological value of SLR (usually the seasonal mean) with a value of SLR produced by a neural network (as is created in Roebber et al. 2003). The forecaster can then use knowledge of the physical processes that determine SLR to surmise the reasons for the discrepancy between the climato- 


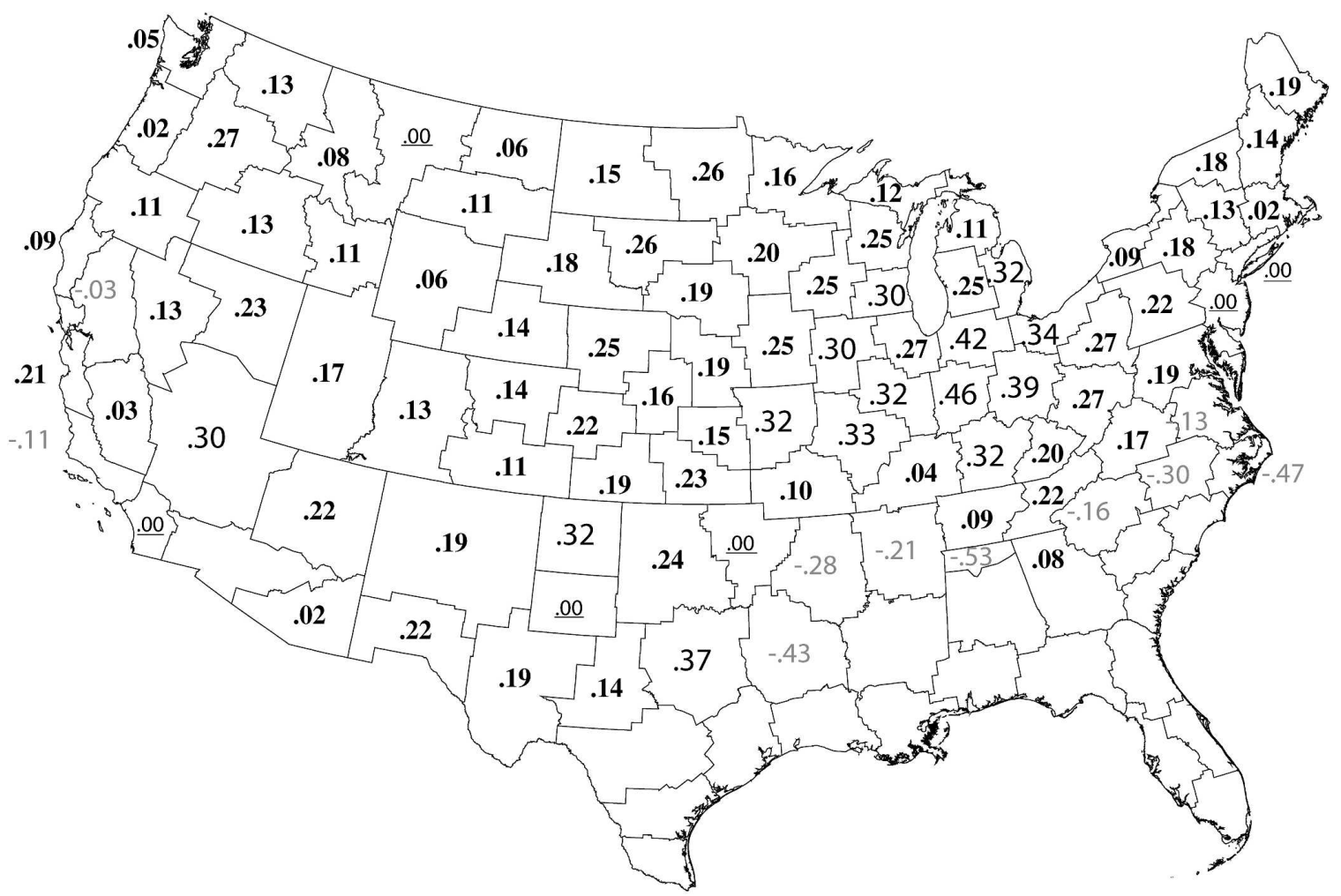

FIG. 17. The Y-K index value for each CWA. Values greater than 0.30 are in larger font. Negative values are in gray. Normal distributions are underlined.

logical value of SLR and the SLR value determined by the neural network. In some cases, particularly when the forecaster has diagnosed the model to be inaccurate, a modification to the climatological value of SLR based upon knowledge of physical processes that determine SLR might prove more felicitous than the use of the neural network SLR value.

Using SLR climatology to construct a physically

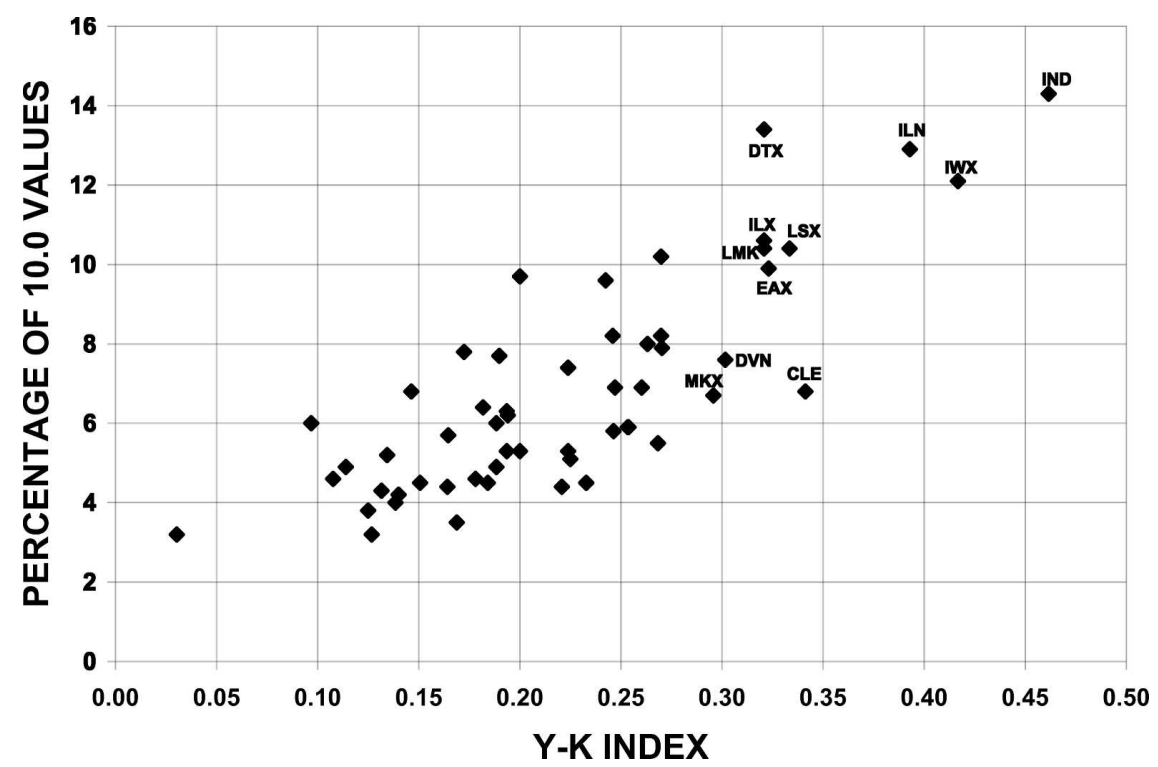

FIG. 18. The Y-K index vs percentage of 10.0 values in each CWA. Labeled values are those effectively greater than 0.30 (MKX is 0.295 ). 
based method for diagnosing SLR is discussed in Baxter et al. (2005, manuscript submitted to Natl. Wea. Dig.). As previous studies have shown, SLR is determined largely by the vertical temperature profile. Thus, the 30-yr mean SLR is likely associated with a mean vertical temperature profile. An SLR value that is higher or lower than the 30 -yr mean is presumably associated with an anomalous vertical temperature profile that is colder or warmer, respectively. The extent the climatological SLR value must be adjusted will depend not only upon the deviation of the temperature profile from the mean temperature profile, but also upon the physical processes that act to determine SLR, such as cold or warm air advection in the lowest levels and the processes that act to alter the ground level temperature. These physical processes will alter the evolution of the ice crystal structure, and thus determine the SLR. The histograms of SLR for each CWA might also provide assistance in determining the degree of deviation from the climatological SLR mean, as they depict the frequency of occurrence of SLR values. Through experience, the forecaster will gain knowledge of the meteorological conditions necessary for the occurrence of less frequent SLR values.

\section{Conclusions}

This study attempted to quantify the statistical properties of SLR for the United States through the creation of a 30-yr (1971-2000) climatology using NWS COOP data. Descriptive statistics were presented for 96 NWS CWAs, along with a discussion of selected histograms of interest.

The climatology provided interesting insights into the characteristics of SLR over an extended time period (1971-2000). The principle finding is that mean SLR values are higher than the often-used mean SLR value of 10. Findings from this study indicate a more appropriate mean SLR value for much of the country to be 13 , although considerable spatial variation in the mean exists. The climatology also quantified SLR values in regions where it has long been known SLR values are fairly high, including Michigan and much of the Rocky Mountains. For these regions an SLR value of 15 is most common. When percentiles of SLR are examined, the distribution is positively skewed. When distributed by season, the same patterns observed in the mean are reflected.

While histograms of SLR for many CWAs mimic the structure of the histogram for the entire dataset, histograms exhibiting considerably different structures can be found. Histograms of SLR that are either shifted toward higher (lower) values or exhibit strong positive (negative) skewness indicate that the CWA frequently features in-cloud, subcloud, and ground conditions that lead to higher (lower) SLR values (as discussed in section 1a). Histograms with a large (small) standard deviation indicate higher (lower) variability in the incloud, subcloud, and ground conditions.

Opportunities for further research on the topic of SLR remain abundant. One avenue for research lies in numerical simulations. Real-time simulations could be used to attempt to develop an algorithm for SLR using information from existing cloud parameterizations. Such an attempt would be difficult, as no solid relationships between thermodynamic and moisture variables have been established. Therefore, the climatological statistics derived in this study might be of use in creating an algorithm, in much the same way climatological information is used in multiple linear regression in the creation of model output statistics.

Acknowledgments. Funding for this research is from the Collaborative Science, Technology, and Applied Research (CSTAR) Program of NOAA under Grant NA03-NWS4680019. The views expressed herein are those of the authors and do not necessarily reflect the view of NOAA or its subagencies. The authors wish to thank Norman W. Junker formerly of NOAA/NCEP/ HPC and David Schultz of NSSL/CIMMS/OU for their insightful comments on previous versions of the manuscript. The authors are also grateful for the comments provided by three anonymous reviewers.

\section{REFERENCES}

Barnes, S. L., 1973: Mesoscale objective analysis using weighted time-series observations. NOAA/National Severe Storms Laboratory Tech. Rep. ERL NSSL-62, 60 pp. [NTIS Com73-10781.]

Bossolasco, M., 1954: Newly fallen snow and air temperature. Nature, 174, 362-363.

Diamond, M., and W. Lowry, 1954: Correlation of density of new snow with 700 millibar temperature. J. Meteor., 11, 512-513.

Doesken, N., and A. Judson, 1996: The Snow Booklet: A Guide to the Science, Climatology, and Measurement of Snow in the United States. Colorado State University, 86 pp.

Grant, L., and J. Rhea, 1974: Elevation and meteorological controls on the density of snow. Interdisciplinary Symp. on Advanced Concepts and Techniques in the Study of Snow and Ice Resources, Monterey, CA, National Academy of Science, 169-181.

Henry, A., 1917: The density of snow. Mon. Wea. Rev., 45, 102113.

Jiusto, J., and H. Weickmann, 1973: Types of snowfall. Bull. Amer. Meteor. Soc., 54, 1148-1162.

Judson, A., and N. Doesken, 2000: Density of freshly fallen snow in the central Rocky Mountains. Bull. Amer. Meteor. Soc., 81, $1577-1587$.

Kind, R., 1981: Snow drifting. Handbook of Snow: Principles, 
Processes, Management, and Use, D. Gray and D. Male, Eds., Pergamon Press, 338-359.

Koch, S. E., M. desJardins, and P. J. Kocin, 1983: An interactive Barnes objective map analysis scheme for use with satellite and conventional data. J. Appl. Meteor., 22, 1487-1503.

LaChapelle, D., 1973: Field Guide to Snow Crystals. University of Washington Press, 101 pp.

LaChapelle, E., 1962: The density distribution of new snow. USDA Forest Service Tech. Rep. 2, Wasatch National Forest, Alta Avalanche Study Center, Project F, Salt Lake City, UT, 13 pp.

Larson, L., and E. Peck, 1974: Accuracy of precipitation measurements for hydrologic modeling. Water Resour. Res., 10, 857862.

Lott, N., 1993: Water equivalent vs. rain gauge measurements from the March 1993 Blizzard. NCDC Tech. Rep. 93-03, 13 pp. [Available online at http://www1.ncdc.noaa.gov/pub/data/ techrpts/tr9303/tr9303.eps.]

Magono, C., and C. Lee, 1966: Meteorological classification of natural snow crystals. J. Fac. Sci., Hokkaido University, II (Series VII), 321-335.

Meister, R., 1986: Density of new snow and its dependence on air temperature and wind. Proceedings of the Workshop on the Correction of Precipitation Measurements, B. Sevruk, Ed.,
E i d -

genossissche Technische Hochschule, 73-80.

Peck, E., 1972: Snow measurement predicament. Water Resour. Res., 8, 244-248.

Potter, J. G., 1965: Water content of freshly fallen snow. Meteorology Branch, Dept. of Transport, CIR-4232, TEC-569, Toronto, ON, Canada, 12 pp. [Available from National Snow and Ice Data Center User Services, University of Colorado, Campus Box 449, Boulder, CO 80309-0449.]

Pruppacher, H., and J. Klett, 1997: Microphysics of Clouds and Precipitation. 2d ed. Kluwer Academic Publishers, 976 pp.

Roebber, P., S. Bruening, D. Schultz, and J. Cortinas, 2003: Improving snowfall forecasting by diagnosing snow density. Wea. Forecasting, 18, 264-287.

Super, A., and E. Holroyd, 1997: Snow accumulation algorithm for the WSR-88D radar: Second annual report. U.S. Dept. of Interior Tech. Rep. Bureau Reclamation R-97-05, Denver, CO, 77 pp. [Available from National Technical Information Service, 5285 Port Royal Rd., Springfield, VA 22161.]

U.S. Department of Commerce, 1996: Supplemental observations. Part IV, National Weather Service Observing Handbook No. 7, Surface Weather Observations and Reports, National Weather Service, Silver Spring, MD, 57 pp.

Wilks, D. S., 1995: Statistical Methods in the Atmospheric Sciences. Academic Press, 465 pp. 